\title{
APLIKASI GAME PETUALANGAN SI KANCIL BERBASIS ANDROID
}

\author{
Erin Masfufah ${ }^{1)}$, M. Ghofar Rohman ${ }^{2)}$, Purnomo Hadi Susilo ${ }^{3)}$ \\ ${ }^{1)}$ Mahasiswa Program Studi Teknik Informatika, Fakultas Teknik, Universitas Islam Lamongan \\ ${ }^{2,3)}$ Dosen Program Studi Teknik Informatika, Fakultas Teknik, Universitas Islam Lamongan \\ Jl. Veteran No. 53 A Lamongan \\ Telp. (0322) 324706 \\ E-mail: erindz02@gmail.com ${ }^{I}$, m.ghofarrohman@unisla.ac.id ${ }^{2}$, hadyjelak.purnomo@gmail.com ${ }^{3}$
}

\begin{abstract}
Games are actually very important for the development of the human brain because a human will start thinking when faced with a problem. While in a game, the user is faced with various problems and required to solve them so that the user can finish or even win the game being played. The purpose of this research is to make adventure genred game with educational content and change the paradigm of the most users about the character of Kancil who is famous by stealing cucumbers because in this game Kancil is portrait trying to collect coins and find golden cucumbersby passing various obstacles on his way. This game is made using Construct 2 application and presented with visual media images completed with good sound to make this game more interesting. This game is as a medium of entertainment. This game is presented in the form of $2 d$ game with apkformat in Android based system. This game is made and given to the users for its usability testing by using questionnaire. This game is very feasible to use in accordance with the final percentage of $91,1 \%$.
\end{abstract}

Keywords: Adventure Game, Kancil, Construct 2, Android.

\section{PENDAHULUAN}

Perkembangan teknologi informasi sangat berperan penting bagi kehidupan manusia, dengan adanya perkembangan teknologi informasi manusia dapat dengan mudah mendapatkan informasi dan melakukan kegiatan sehari-hari dengan bantuan teknologi yang ada. Salah satunya yaitu teknologi smartphone yang telah berkembang pesat dengan berbagai macam sistem operasi yang telah tersedia. Android merupakan sistem operasi yang berbasis linux untuk telepon seluler seperti smartphone dan komputer tablet. Android menyediakan platform terbuka bagi para pengembang untuk menciptakan aplikasi mereka sendiri sesuai dengan kebutuhan dan keinginannya. Salah satunya game platform Android yang sangat berkembang pesat saat ini [1].

Beberapa tahun belakangan ini, industri game semakin marak dengan munculnya game yang semakin menarik dan berkualitas dari segi visualisasi maupun dari segi cerita, dimana banyak game yang beredar pada industri saat ini adalah termasuk buatan asing. Namun dengan perkembangan game saat ini yang sangat pesat, sangat disayangkan para pengguna game khususnya di Indonesia masih sering menggunakan game-game buatan asing. Alangkah bangganya jika masyarakat Indonesia mencintai produk dalam negeri khususnya game buatan anak Indonesia [2].

Game atau permainan adalah sesuatu yang dapat dimainkan dengan aturan tertentu sehingga ada yang menang dan ada yang kalah, biasanya dalam konteks tidak serius dengan tujuan refreshing. Bermain game sudah dapat dikatakan sebagai life style masyarakat dimasa kini. Dimulai dari usia anak-anak hingga orang dewasa pun menyukai video game. Itu semua dikarenakan bermain video game adalah hal yang menyenangkan [3].

Game terdiri dari beberapa genre (jenis). Banyak dari game yang dibuat dengan menggabungkan beberapa genre agar cerita game tersebut menjadi lebih menarik dan memuaskan yang memainkannya. Agar lebih memahami tentang genre (jenis-jenis) game, berikut ini akan dijelaskan macammacam genre game tesebut:

\section{a) Adventure (Petualangan)}

Merupakan genre game yang bertema petualangan dan menceritakan kisah perjalanan seseorang untuk mencapai sesuatu yang diinginkannya. 


\section{b) Fighting (Pertarungan)}

Seperti namanya game ini hanya menerapkan sistem pertarungan satu lawan satu, dimana harus mengalahkan lawan tanding untuk memenangkan pertandingan.

\section{c) Racing}

Genre ini merupakan permainan yang bersifat perlombaan karena hanya butuh melewati garis finish untuk memenangkan pertandingan. Terdapat beberapa lap (putaran) yang harus diselesaikan, jadi tugas pemainnya hanyalah terus tancap gas dan berjalan mulus di area lintasan balap.

\section{d) Shooting}

Aksi tembak-menembak merupakan tema utamanya, karena tujuan dalam game jenis ini hanya untuk membunuh lawan ataupun musuh dengan senjata yang telah disediakan.

\section{e) Simulation}

Game simulasi merupakan genre game yang berisi tentang simulasi. Contoh simulasinya antara lain tentang simulasi menjalankan sebuah kendaraan maupun simulasi kehidupan sendiri.

\section{f) Sport}

Merupakan jenis game yang memiliki unsur olahraga di dalamnya. Banyak sekali olahraga di dunia nyata yang dimasukkan ke dalam game, sehingga tidak hanya dapat berolahraga seperti biasa, namun juga dapat dilakukan dengan dalam video game.

\section{g) Strategy}

Memainkan jenis game ini dibutuhkan keterampilan yang cukup baik, karena di dalam permainan ini diharuskan memiliki strategi yang sesuai untuk menentukan langkah-langkah yang harus diambil demi memenangkan pertempuran.

\section{h) RPG (Role Playing Game)}

Merupakan jenis game yang didalamnya terdapat seorang tokoh nama untuk diperankan. Biasanya kisah ini menceritakan tentang kehidupan suatu dunia atau untuk mencari barang suci yang menjadi penentuan nasih sebuah dunia [4].

Games sebenarnya sangat penting untuk perkembangan otak manusia. Seorang manusia akan mulai berpikir jika sudah dihadapkan dengan sebuah masalah. Sedangkan pada sebuah games, user dihadapkan dengan berbagai macam masalah dan dituntut untuk memecahkannya sehingga dapat menyelesaikan atau bahkan user dapat memenangkan permainan/games yang di mainkan[5].

Ada beberapa software yang bisa digunakan untuk membuat game/game engine, seperti : Cry Engine 3, Unreal Development Kit ( UDK), Source Engine, Game Maker Studio dan Construct 2. Construct 2 adalah game editor berbasis HTML5 yang dikembangkan oleh Scirra Ltd yang memaksimalkan fungsi visual editor dan behaviour-based logic system, construct 2 dapat digunakan untuk membuat game tanpa harus menulis kode pemrograman. Kelebihan lain dari construct adalah fungsifungsi bawaan yang sudah disediakan dapat mempercepat proses pembuatan game.

Berikut beberapa software yang dibutuhkan dalam pembuatan game petualangan si kancil berbasis android antara lain:

\section{Construct 2}

Construct 2 adalah tools yang digunakan dalam membuat sebuah game tanpa memerlukan pengetahuan tentang pemrograman. caranya hanya melakukan drag and drop item yang tersedia, menambahkan perilaku mereka, dan membuat mereka menjadi bergerak dengan sebuah event. Construct 2 memiliki interface yang sangat mirip dengan produk microsoft office. hal ini membuat mudah bagi orangorang yang terbiasa dengan produk office. karena sifat HTML 5 masih eksperimental, ada beberapa fitur dalam pembuatan game yang mungkin tidak bekerja dengan baik di semua perangkat. Construct 2 merupakan tools yang dapat dipelajari dengan cepat, dalam pembuatan game dapat dilakukan dengan mengekspor permainan sendiri dan bekerja dalam mobile device [6].

\section{HTML 5}

HTML5 adalah generasi terbaru setelah HTML sebagai generasi penerus HTML 4.01, XHTML 1.0, dan XHTML 1.1. HTML5 menyediakan fitur baru yang diperlukan untuk aplikasi web modern. Hal ini juga menjadi fitur standar dari platform web yang telah diterapkan oleh pengembang 
web selama bertahun-tahun. Akan tetapi hal itu tidak pernah diperiksa atau didokumentasikan menjadi sebuah standar baku dari teknologi HTML. Seperti generasi sebelumnya, HTML5 dirancang untuk crossplatform [7].

\section{Adobe Photoshop}

Adobe Photoshop merupakan sebuah software pengolah foto yang sangat populer dan sudah banyak pengguna software grafis ini yang mengakui kehebatannya. Fitur andal dan kemudahan pengguna fasilitas di dalamnya menjadikan Photoshop sebagai poineer dalam pengolahan grafis. perangkat lunak ini pun banyak digunakan oleh photografer digital dan perusahaan iklan sehingga dianggap sebagai pemimpin pasar (market leader) untuk perangkat lunak pengolah gambar. Bahkan bersama Adobe Acrobat, dianggap sebagai produk terbaik yang pernah diproduksi Adobe Systems [8].

\section{Android}

Android merupakan sistem operasi smartphone yang begitu populer akhir-akhir ini. Keunggulan utama dari sistem operasi ini adalah dukungan aplikasi yang sangat banyak dan banyak dari aplikasi itu yang bersifat gratis.

Android adalah nama sebuah sistem operasi berbasis Linux yang ditujukan untuk perangkat bergerak dengan layar sentuh seperti smartphone dan komputer tablet. Awalnya android dibuat oleh perusahaan Android Inc. Sampai akhirnya diakusisi oleh Google pada tahun 2005. Berkat Google, kini Android semakin populer, terlebih lisensi yang digunakan adalah lisensi open source. Ikon android juga cukup terkenal, yaitu robot berwarna hiaju [9].

Berdasarkan latar belakang di atas, maka penulis tertarik membuat game yang berjudul "Petualangan Si Kancil" yang bisa menjadi media hiburan juga sangat menarik disertai dengan edukasi, nyaman untuk dimainkan, serta cocok untuk segala umur.
Pembuatan game ini menggunakan Construct 2 dan diimplementasikan pada smartphone Android.

Meninjau latar belakang masalah di atas, maka yang menjadi pokok permasalahan adalah:

1. Bagaiman cara membuat game bergenre petualangan dengan adanya muatan edukasi didalam game tersebut.

2. Bagaiman cara melatih perkembangan otak manusia.

3. Bagaiman cara memotifasi anak dalam berusaha mendapatkan sesuatu.

Adapun tujuan penelitian ini antara lain adalah:

1. Untuk membuat game ber-genre petualangan dengan adanya muatan edukasi didalam game tersebut.

2. Untuk melatih perkembangan otak manusia karena seorang manusia akan mulai berpikir untuk menyelesaikannya jika sudah dihadapkan dengan sebuah masalah dalam game tersebut.

3. Untuk memotifasi anak dalam berusaha mendapatkan sesuatu.

\section{METODE PENELITIAN}

Usecase diagram pada Gambar 1 menggambarkan fungsionalitas yang diharapkan dari aplikasi game petualangan si kancil menggunakan platform android, kebutuhan sistem dari sudut pandang pengguna serta hubungan antara actor dan usecase. Disini usecase menggambarkan aktor yang masuk ke menu play game dan memulai level awal dari game setelah itu ada sounds untuk mengganti on atau off suara pada game petualangan si kancil dan menu help yang mendeskripsikan cara main game ada juga menu about untuk melihat deskripsi mengenai pembuat game setelah itu ada tombol quit apabila pemain ingin keluar dari proses game. 


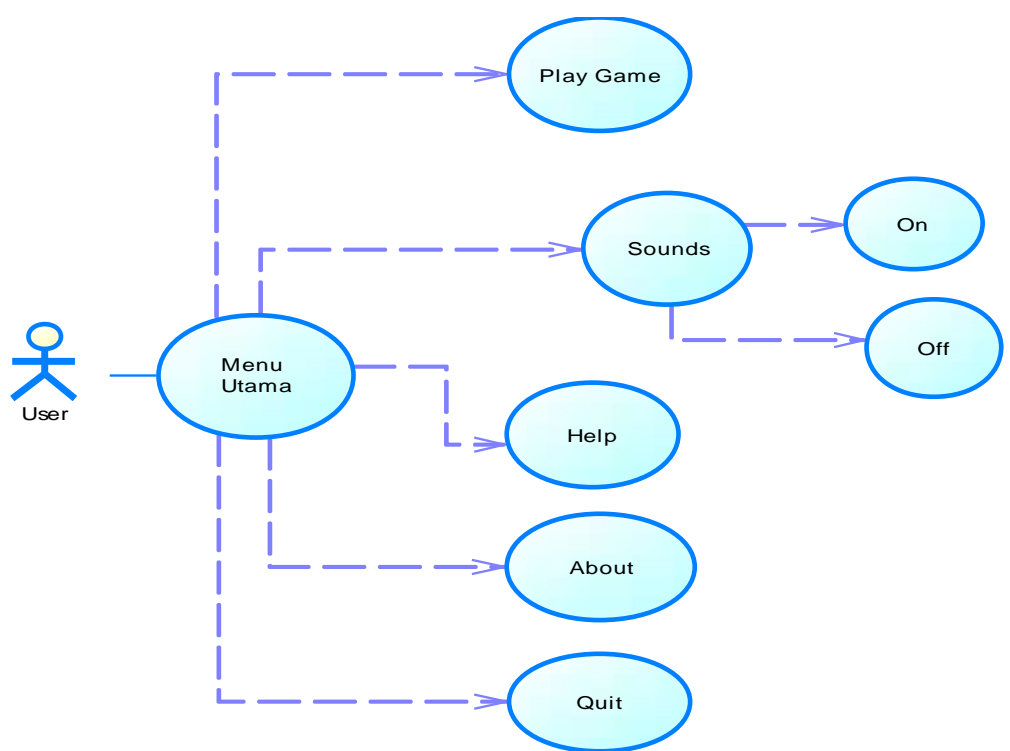

Gambar 1. Usecase Diagram Aplikasi Game Petualangan Si Kancil Berbasis Android

\section{berikut:}

Deskripsi usecase di atas sebagai

1. Play Game : pemain mulai permainan dari level 1 dan jika level 1 sudah terselesaikan baru bisa melanjutkan ke level berikutnya sampai level 5 .

2. Sounds: pemain dapat mengatur suara (on) atau dimatikan (off).

3. Help: pemain dapat membaca keterangan cara memainkan permainan ini.

4. About : pemain dapat melihat deskripsi mengenai pembuat game.

5. Quit: pemain dapat keluar dari permainan melalui menu ini.

Berikut rancangan storyboard game yang terdapat pada game Petualangan Si Kancil:

\section{Level 1}

Pemain harus melewati jebakan agar tetap bisa melanjutkan permainan. Di level 1 ini terdapat 5 jebakan. Pemain juga harus mengumpulkan koin untuk menambah skor. Di level 1 ini berjumlah 15 koin dan ada timun setiap levelnya untuk menambah satu nyawa pemain dan harus memusnahkan musuh untuk lanjut ke level selanjutnya background game di hutan.

2. Level 2

Pada level ini jebakan yang diberikan semakin banyak Pemain harus melewati jebakan tersebut karena jika gagal melewati jebakan tersebut maka akan mengulangi permainan. Di level 2 ini terdapat 6 jebakan. Pemain juga harus mengumpulkan koin untuk menambah skor. Di level 2 ini berjumlah 30 koin dan ada timun setiap levelnya untuk menambah satu nyawa pemain dan harus memusnahkan musuh untuk lanjut ke level selanjutnya.

3. Level 3

Pada level ini jebakan bertambah menjadi 7 jebakan. pemain harus melewatinya untuk melanjutkan ke level berikutnya. Pemain juga harus tetap mengumpulkan koin yang berjumlah 40 untuk manambah skor dan ada timun setiap levelnya untuk menambah satu nyawa pemain dan harus memusnahkan musuh untuk lanjut ke level selanjutnya.

\section{Level 4}

Pada level ini jebakan yang diberikan bertambah menjadi 10 , pemain harus melewatinya untuk melanjutkan ke level berikutnya. Pemain juga harus tetap mengumpulkan koin yang berjumlah 45 untuk manambah skor dan ada timun setiap levelnya untuk menambah satu nyawa pemain dan harus memusnahkan musuh untuk lanjut ke level selanjutnya.

\section{Level 5}

Pada level ini jebakan juga semakin bertambah menjadi 12 dan harus mengumpulkan koin yang berjumlah 45 . Pada level terakhir ini, jika pemain berhasil maka dapat mengambil Timun Emas karena ini merupakan misi akhir game ini, yaitu mendapatkan Timun Emas. Di level 
terakhir ini pemain juga harus tetap mengumpulkan koin.

Berikut ini adalah ruang lingkup dari game petualangan si kancil:

a) Game dapat menampilkan menu utama, menu Play Game, Sounds menu help, menu about dan Menu Quit.

b) Suara pada game dapat dimatikan.

c) Progress game dapat di reset ulang.

d) Game dapat di-close dan di-pause.

e) Game dapat menampilkan score yang berupa berapa banyak koin yang didapat pada masing-masing level.

f) Game "Petualangan $\mathrm{Si}$ Kancil" memiliki 5 level yang masing-masing level memiliki kerumitan yang berbeda.

g) Game akan dinyatakan sukses bila sudah menemukan timun emas.

h) Nyawa game akan berkurang bila terkena jebakan dan musuh.

Analisis ini digunakan untuk menganalis data dari hasil penyebaran kuesioner yang diberikan kepada para ahli dalam menilai produk.

Keterangan:

V :Validitas

$\sum$ TSEV :Total skor empirik validator

$\sum$ S-max :Skor maksimal yang diharapkan 100\% : Bilangan constant

Pada Tabel 1 dapat dilihat pada Kriteria atau kesimpulan pencapaian hasil produk yang dikembangkan.

Tabel 1. Tabel Kriteria Validitas Produk

\begin{tabular}{|c|c|c|}
\hline Pencapaian \% & $\begin{array}{c}\text { Tingkat } \\
\text { Validitas }\end{array}$ & Keterangan \\
\hline $75,01 \%-100 \%$ & Valid & $\begin{array}{c}\text { Dapat digunakan } \\
\text { tanpa revisi }\end{array}$ \\
\hline $50,01 \%-75 \%$ & $\begin{array}{l}\text { Cukup } \\
\text { Valid }\end{array}$ & $\begin{array}{l}\text { Dapat } \\
\text { digunakan } \\
\text { namun perlu } \\
\text { revisi kecil }\end{array}$ \\
\hline $25,01 \%-50 \%$ & $\begin{array}{l}\text { Tidak } \\
\text { Valid }\end{array}$ & $\begin{array}{l}\text { Tidak boleh } \\
\text { digunakan/perl } \\
\text { u revisi besar }\end{array}$ \\
\hline $0 \%-25 \%$ & $\begin{array}{r}\text { Sangat } \\
\text { Tidak } \\
\text { Valid }\end{array}$ & $\begin{array}{c}\text { Tidak boleh } \\
\text { digunakan/revi } \\
\text { si total }\end{array}$ \\
\hline
\end{tabular}

Analisis ini digunakan untuk mengetahui hasil yang diperoleh dari kuesioner yang disebarkan kepada para pengguna game yang dibuat dan dikembangkan penelti menggunakan rumus. Adapun rumusnya adalah sebagai berikut:

$\mathrm{P}=\frac{\sum \mathrm{X}}{\sum \mathrm{xi}} \times 100 \%$

Keterangan:

$\mathrm{P} \quad$ : Skor persentase

$\sum \mathrm{x} \quad$ : Jumlah keseluruhan responden

$\sum x i$ : Jumlah keseluruhan nilai ideal suatu item 100\% : Bilangan konstanta

Kemudian untuk menentukan kriteria pencapaian hasil produk yang dikembangkan dapat dilihat pada Tabel 2.

Tabel 2. Kriteria Usability Produk

\begin{tabular}{|c|c|c|}
\hline $\begin{array}{c}\text { Pencapaian } \\
\%\end{array}$ & $\begin{array}{l}\text { Tingkat } \\
\text { Capaian }\end{array}$ & Keterangan \\
\hline $81 \%-100 \%$ & $\begin{array}{l}\text { Sangat } \\
\text { Layak }\end{array}$ & $\begin{array}{l}\text { Dapat } \\
\text { digunakan/sangat } \\
\text { mudah digunakan }\end{array}$ \\
\hline $61 \%-80 \%$ & Layak & $\begin{array}{c}\text { Dapat } \\
\text { digunakan/mudah } \\
\text { digunakan }\end{array}$ \\
\hline $41 \%-60 \%$ & $\begin{array}{l}\text { Cukup } \\
\text { Layak }\end{array}$ & $\begin{array}{l}\text { Disarankan tidak } \\
\text { digunakan/cukup } \\
\text { mudah digunakan }\end{array}$ \\
\hline $21 \%-40 \%$ & $\begin{array}{l}\text { Tidak } \\
\text { Layak }\end{array}$ & $\begin{array}{c}\text { Tidak boleh } \\
\text { digunakan/sulit } \\
\text { untuk digunakan }\end{array}$ \\
\hline $0 \%-20 \%$ & $\begin{array}{l}\text { Sangat } \\
\text { Tidak } \\
\text { Layak }\end{array}$ & $\begin{array}{c}\text { Tidak boleh } \\
\text { digunakan/sangat } \\
\text { sulit untuk } \\
\text { digunakan } \\
\end{array}$ \\
\hline
\end{tabular}

a) Analisis perangkat keras

Adapun spesifikasi dari alat yang digunakan untuk pembuatan game petualangan si kancil ini adalah :

- Komputer dengan Processor Intel ${ }^{\circledR}$

Core(TM) i5-2520M CPU @

$2.50 \mathrm{GHz}$ (4 CPUs), $\sim 2.5 \mathrm{GHz}$

- $\quad$ Memory (RAM) 4.00 GB

- $\quad$ VGA Mobile Intel® HD Graphics 3000

- $\quad$ Hard Disk 500GB

b) Analisis perangkat lunak

Perangkat lunak yang digunakan dalam pembangunan game ini adalah : 
- $\quad$ Operating System: Windows 7

- $\quad$ Game Editor : Construct 2

- Image Editor: Adobe Photoshop

- $\quad$ Sound Editor : Adobe Audition

\section{HASIL DAN PEMBAHASAN}

Game yang dibuat terdiri dari beberapa layout yang berisi berbagai menu yang dibutuhkan seperti : menu play game yang terdapat beberapa level mulai dari level 1 sampai 5 semuanya memiliki karakteristik yang berbeda-beda sehingga membuat game semakin menarik ketika dimainkan, yaitu ketika naik ke level berikutnya maka akan ada rintangan yang lebih banyak, proses lebih jelasnya akan diuraikan pada penjelasan di bawah ini.

Tampilan loading game ini berfungsi sebagai splash screen waktu tunggu saat awal pertama membuka Game Petualangan Si Kancil. Splash screen sebagai intro dari sebuah aplikasi berperan penting untuk menambah kredibilitas aplikasi. Gambar splash screen sebisa mungkin disajikan secara menarik dan ringan agar pengguna tertarik pada aplikasi game tersebut. Berikut adalah tampilannya yang ditunjukkan pada Gambar 2 di bawah ini.

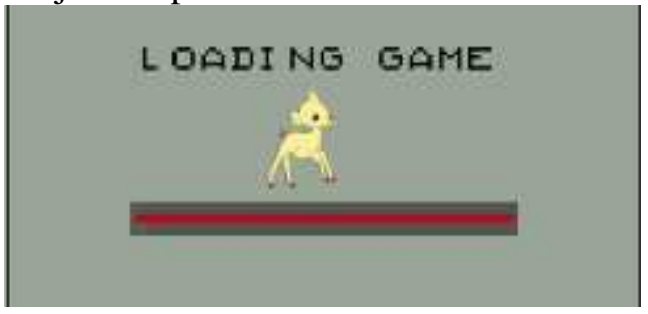

Gambar 2. Loading game Petualangan Si Kancil

Tampilan menu utama pada game petualangan si kancil tersebut terdapat lima menu yang antara lain menu play game berisi 5 level, menu Help yang berisi petunjuk dan rintangan pada permainan, menu about berisi data diri programmer, menu sound berisi perintah on atau off suara, dan menu exit ketika ingin keluar dari aplikasi game tersebut. Lebih jelasnya bisa dilihat pada Gambar 3 di bawah ini.

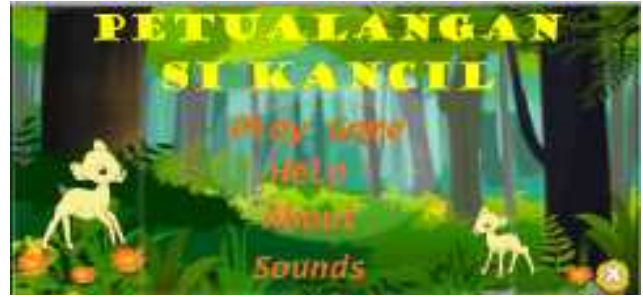

Gambar 3. Menu Utama Game Petualangan Si Kancil

Tampilan level 1 merupakan level awal yang rintangannya lebih mudah, game ini dimulai dari seekor kancil yang mempunyai misi untuk menemukan timun emas, nyawa musuh pertama yaitu kecoa ada satu sehingga untuk melanjutkan level kedua, pemain harus bisa membasmi kecoa tersebut hingga nyawanya habis dan ketika nyawa habis maka pemain akan menemukan petunjuk sebuah tanda panah untuk melanjutkan ke level selanjutnya. Pemain juga dapat memperbanyak point dengan mengumpulkan beberapa koin emas yang ada pada setiap perjalanannya. Kemudian untuk penjelasan tombol-tombol yang ada pada level 1 tersebut terdapat tambahan tombol pause ketika pemain ingin melakukan pemberhentian sejenak pada permainan yang dimainkan, terdapat tombol on atau off suara pada permainan serta terdapat tombol home yang berfungsi untuk kembali ke menu utama game. Berikut adalah Gambar 4 yang menunjukkan level 1 game.

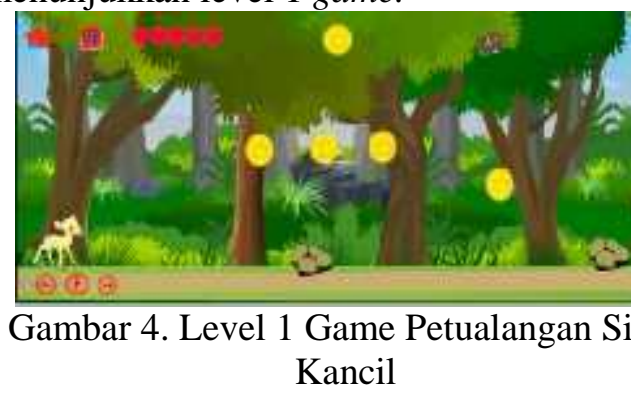

Dalam level ini terdapat pertanyaan yang harus di jawab, apabila pemain menjawab dengan benar yaitu memilih kancil maka sistem akan melanjutkan ke level 2 tetapi apabila pemain memilih jawaban yang salah maka sistem akan merestart ulang permainan yang sedang dimainkan. Berikut adalah Gambar 5 yang menunjukkan tampilan quiz game. 


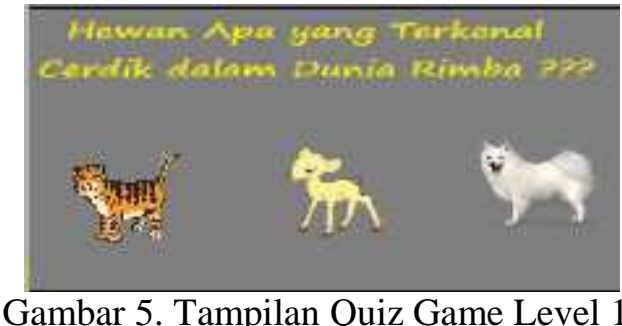

Apabila pemain sudah melewati semua rintangan mulai level satu sampai level lima maka pemain akan sampai di akhir misi yaitu menemukan timun emas. Berikut adalah Gambar 6 yang menunjukkan tampilan misi complete.

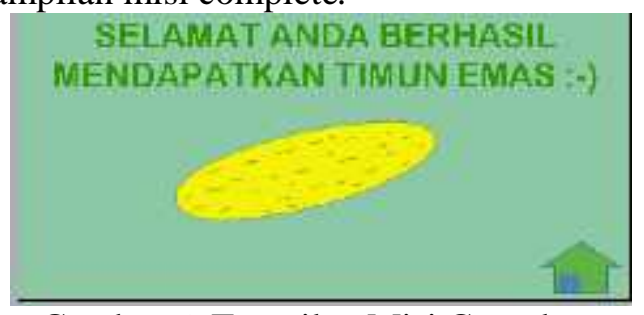

Gambar 6. Tampilan Misi Complete

Tampilan tersebut akan muncul ketika pemain berhasil menyelesaikan level permainan, jumlah bintang yang dipeoleh sesuai dengan score yang didapat oleh pemain yaitu antara lain : pada level 1 mendapat bintang 1 dengan score 1-10, bintang 2 dengan score 11-25, dan bintang 3 dengan score lebih dari 26 untuk level seterusnya jumlah score yang harus di dapat juga semakin bertambah. Berikut adalah tampilannya yang ditunjukkan Gambar 7 di bawah ini.

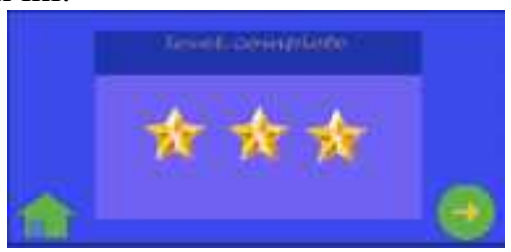

Gambar 7. Level complete

Tampilan tersebut akan muncul ketika pemain gagal dan nyawa pemain tersebut habis pada saat memainkan level permainan, berikut adalah tampilannya yang ditunjukkan Gambar 8 di bawah ini.

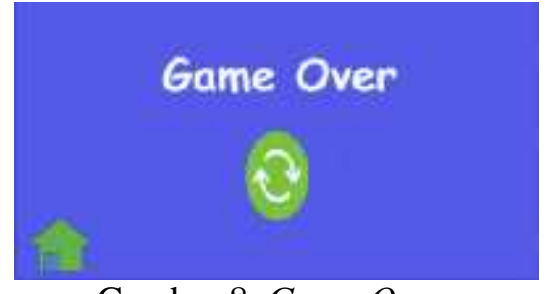

Gambar 8. Game Over

Menu help tersebut berisi penjelasan lebih detailnya untuk melakukan permainan agar pemain bisa menyelesaikan misi sesuai dengan alur permainan yang dibuat. Berikut untuk lebih jelasnya dapat dilihat pada Gambar 9 di bawah ini.

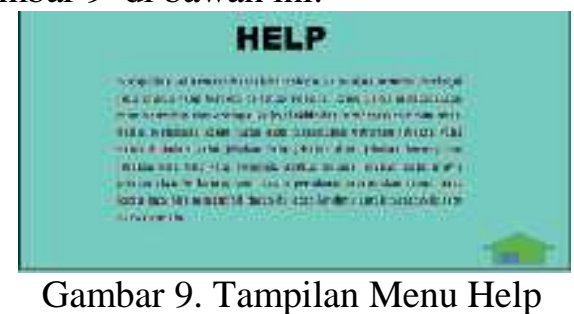

Gambar 10 merupakan tampilan menu about yang menampilkan data diri programmer, berikut tampilan lebih jelas dari gambar tersebut yaitu di bawah ini.

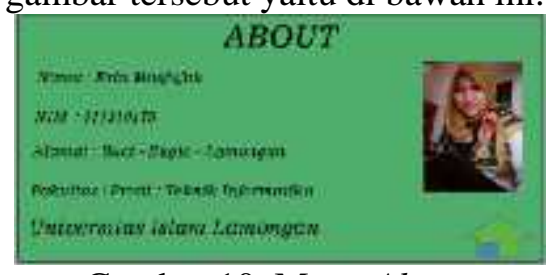

Gambar 10. Menu About

Tampilan menu Exit akan muncul ketika pemain ingin keluar dari program aplikasi berikut tampilannya yang ditunjukkan pada Gambar 11 di bawah ini.

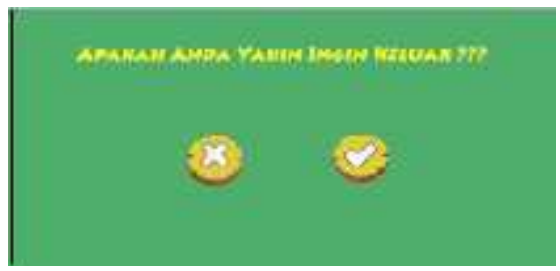

Gambar 11. Menu Exit

Berikut ini adalah perhitungan kuesioner berdasarkan usability testing sesuai dengan pilihan jawaban dan perolehan skor yang diperoleh dari penyebaran kuesioner terhadap 20 responden. Sebelum memperoleh hasil total dari presentase kuesioner tentukan nilai $\sum \mathrm{x}, \sum \mathrm{xi}$, dan $\mathrm{P} \%$ 
dari keseluruhan pertanyaan dari kuesioner yang disebarkan kepada 20 responden seperti yang ditunjukkan Tabel 8 di bawah ini.

Tabel 3. Perolehan P\% dari Masing-masing Responden

\begin{tabular}{ccccc}
\hline No & $\begin{array}{c}\text { Pertanyaan } \\
\text { ke- }\end{array}$ & $\sum \mathrm{x}$ & $\sum \mathrm{xi}$ & $\begin{array}{c}\mathrm{P} \%= \\
\sum \mathrm{x}: \sum \mathrm{xi}\end{array}$ \\
\hline 1 & $\mathrm{P} .1$ & 73 & 80 & $91,25 \%$ \\
2 & $\mathrm{P} .2$ & 71 & 80 & $88,75 \%$ \\
3 & $\mathrm{P} .3$ & 78 & 80 & $97,5 \%$ \\
4 & $\mathrm{P} .4$ & 67 & 80 & $83,75 \%$ \\
5 & $\mathrm{P} .5$ & 76 & 80 & $95 \%$ \\
6 & $\mathrm{P} .6$ & 73 & 80 & $91,25 \%$ \\
7 & $\mathrm{P} .7$ & 72 & 80 & $90 \%$ \\
8 & $\mathrm{P} .8$ & 74 & 80 & $92,5 \%$ \\
9 & P.9 & 76 & 80 & $95 \%$ \\
10 & $\mathrm{P} .10$ & 73 & 80 & $91,25 \%$ \\
11 & $\mathrm{P} .11$ & 69 & 80 & $86,25 \%$ \\
\hline
\end{tabular}

Setelah memperoleh nilai $\sum \mathrm{x}, \sum \mathrm{xi}$, dan P\% dari pertanyaan ke-1 sampai pertanyaan ke-11 maka, dapat dicari hasil total presentase kuesioner sesuai dengan rumus yang dapat dilihat pada metodologi penelitian yang ada pada BAB I. Berikut adalah hasil perhitungan yang didapat.

$$
\begin{aligned}
\mathbf{P}= & \sum \times 1+\sum \times 2+\sum \times 3+\sum \times 4+\sum \times 5+\sum \times 6+\sum \times 7 \\
& +\sum \times 8+\sum \times 9+\sum \times 10
\end{aligned}
$$

$$
\begin{aligned}
& \sum \mathbf{x i}-\mathbf{m a x} \\
= & \frac{73+71+78+67+76+73+72+74+76+73+69}{4.11 .20} \\
& =802 / 880 \\
& =0,91 \times 100 \% \\
& =91,1 \%
\end{aligned}
$$

Sesuai perhitungan di atas jadi, dapat ditarik kesimpulan bahwa aplikasi game yang dibuat peneliti sangat tinggi atau sangat layak dengan presentase nilai yaitu $91,1 \%$.

\section{KESIMPULAN}

Berdasarkan hasil permasalahan serta pembahasan yang telah diuraikan dalam bab sebelumnya, maka kesimpulan yang dapat di ambil adalah sebagai berikut: Telah dibuat dan dirancang game petualangan si kancil yang bisa menjadi media hiburan, nyaman untuk dimainkan, serta cocok untuk segala umur. Pembuatan game ini menggunakan Construct 2 dan diimplementasikan pada smartphone Android. Setelah di uji dengan metode black box testing dan metode kuesioner maka dihasilkan sebagai berikut:

a) Pada pengujian Black box testing yang telah dibuat oleh peneliti menunjukan penelitian ini telah sesuai dengan perancangan yang telah dikonsep sebelumnya yang terlihat dari hasil pengujian. Game ini layak sebagai media hiburan bagi anak-anak dan remaja.

b) Pada pengujian penerimaan menggunakan metode kuisioner yang dilakukan terhadap pengguna atau user hasil prosentase yang di dapat yaitu 91,1 $\%$ menunjukan tingkat respon pengguna sangat tinggi untuk memainkan game ini dan game tersebut sangat layak digunakan.

\section{REFERENSI}

[1] Putra, Arvian Try Baskara, 2016, Perancangan dan Pembuatan Game "Arrange The Number" Berbasis Android Menggunakan Game Engine Construct 2. Naskah Publikasi, Teknik Informatika Sekolah Tinggi Manajemen Informatika dan Komputer Amikom Yogyakarta, Yogyakarta.

[2] Pratama, Wahyu, 2014, Misteri Kotak Pandora, Skripsi, Teknik Informatika STMIK AMIKOM, Purwokerto No. 2, Vol 7.

[3] Kurniawan, ajie irsadi, 2011, Analisis Perancangan dan Pembuatan Game Poheng Adventure, Naskah Publikasi, Sekolah Tinggi Manajemen Informatika dan Komputer AMIKOM Yogyakarta, Yogyakart

[4] Sumartono, Agus dan Lutfi, Ahmad, 2014, Pembuatan Game Edukasi Platformer Perjalanan Mimpi Alfi Menggunakan Construct 2, Naskah Publikasi, Teknik Informatika Sekolah Tinggi Manajemen Informatika dan Komputer AMIKOM Yogyakarta, Yogyakarta. 
[5] Rahmat, Mulkrim, 2014, Pengaruh Game Terhadap Kinerja Otak, https: //mulkrim

wordpress.com/2014/02/27/pengaruh -game-terhadap=kinerja-otak/, diakses pada tanggal 9 juni 2017, pukul 12.03 .

[6] Istiqomah, Dewi Anisa, 2014, Aplikasi Game SusunAaksara Jawa (suraja) Sbagai Media Belajar Aksara Jawa Kelas V SDIT Salsabila Baiturrahman untuk Platform Android, Skripsi, Teknik Informatika Universitas Negeri Yogyakarta, Yogyakarta.
[7] Aji, Damar Yosa, 2016, Pengenalan HTML5,https://www.codepolitan.co $\mathrm{m} /$ tutorial/pengenalan-html5-belajarhtml, diakses pada tanggal 9 juni 2017, pukul 12.10.

[8] Waloeya, Yohan Jati, 2013, Hebat Mengedit dengan Adobe Photoshop CS6, ANDI Yogyakarta dan ELCOM Yogyakarta.

[9] Wahana Komputer, 2013, Kupas Tuntas Aplikasi Android Bagi Penggila Travelling, ANDI Yogyakarta dan Wahana Komputer Semarang. 
---Halaman ini sengaja dikosongkan--

66|P a g e 